\title{
Relationship between the Noto-Peninsula earthquake and maternal postnatal depression and child-rearing
}

\author{
Yuri Hibino · Jiro Takaki · Yasuhiro Kambayashi · \\ Yoshiaki Hitomi · Akemi Sakai · Naomi Sekizuka • \\ Keiki Ogino $\cdot$ Hiroyuki Nakamura
}

Received: 11 February 2009/Accepted: 6 May 2009/Published online: 4 June 2009

(C) The Japanese Society for Hygiene 2009

\begin{abstract}
Objective The aim of our study was to explore the relationship between a medium-scale earthquake and maternal depression and child-rearing in a depopulated community in the Noto Peninsula of Japan.

Methods Three months after a major earthquake, selfrating questionnaires were distributed to women who were pregnant at the time of the earthquake or who became pregnant immediately thereafter, and who were receiving care at any of four major hospitals in the most devastated area. A total of 155 women who had given birth returned the completed questionnaire for analysis. Maternal postnatal depression among the participants was assessed using the Edinburgh Postnatal Depression Scale (EPDS).

Results The EPDS score was significantly associated with decreased "satisfaction with delivery" $(\beta=-0.28$, $p=0.01)$, increased artificial "lactation" $(\beta=0.31$, $p=0.002)$, and increased "trouble with infant care" $(\beta=0.47, p<0.001)$ in multivariate analysis. It was also significantly associated with increased "anxiety about earthquakes" ( $\beta=0.30, p=0.001)$, and "anxiety about
\end{abstract}

Y. Hibino $(\varangle) \cdot$ Y. Kambayashi · Y. Hitomi · H. Nakamura Department of Environmental and Preventive Medicine, Graduate School of Medical Science, Kanazawa University, 13-1 Takaramachi, Kanazawa, Japan

e-mail: hibino@pub.m.kanazawa-u.ac.jp

J. Takaki $\cdot$ K. Ogino

Department of Public Health,

Okayama University Graduate School of Medicine,

Dentistry and Pharmaceutical Sciences, Okayama, Japan

A. Sakai · N. Sekizuka

Department of Health Science,

Graduate School of Medical Science,

Kanazawa University, Kanazawa, Japan earthquakes" was significantly associated with increased "fear of the earthquake" ( $\beta=0.20, p=0.04)$.

Conclusions Earthquake-related factors such as "anxiety about earthquakes" and "fear of the earthquake" did not have a direct effect on child-rearing factors; however, they did have a significant relationship with increased EPDS. Based on these results, we conclude that screening strategies for maternal depression in peri- and postnatal women under emergency circumstances are necessary.

Keywords Child-rearing - Depopulated · Earthquake . Maternal postnatal depression

\section{Introduction}

The Noto Peninsula area is located in northern Japan and consists of a depopulated community with a large elderly population. On March 25, 2007, an earthquake measuring 6.9 on the Richter magnitude scale struck the area, severely damaging the region and completely destroying 684 houses. More than 2500 people had to move to temporary shelters. A large proportion of the residents in this area are elderly, reaching slightly more than $50 \%$ in one region. However, 1000 neonates on average are born each year in the Noto Peninsula, so the effects of disaster-related stress on perinatal women cannot be ignored.

Numerous studies have addressed the various health problems caused by devastating earthquakes [1-5]. Of these, few have examined the effects of disaster-related stress on perinatal women [6-9]. The findings of these earlier studies suggest that prenatal stress caused by natural and man-made disasters may result in minor psychiatric distress [3, 4], low birth weight [7], preterm delivery [6, 10], smaller head circumference [6, 7], skewed sex ratios 
[9], retardation of fetal brain development [11], and reduction of breast milk supply [8]. It also would seem that pregnant women are more susceptible to the effects of stress in the first trimester than in the second and third trimesters $[6,10,12]$.

Stress exposure during the perinatal period may worsen maternal psychological health, and this in turn may lead to degradation of the quality of care toward the newborn infant. There is evidence to suggest that maternal psychosocial health can have a significant effect on the motherinfant relationship and that this can have consequences for both the short and long-term health of the child under ordinary circumstances [13-16]. Despite this evidence, however, studies on the effects of earthquake exposure on maternal psychological health and the mothering of a new born baby have been limited.

Several of the earlier studies have indicated that natural disaster stress affects parental psychological health and family function and that this correlates with the children's mental health $[17,18]$. One study found that child abuse reports were disproportionately higher after the occurrence of a natural disaster [19]. Mental health status can therefore be transmitted from generation to generation. However, this perspective has only rarely been examined in the earlier earthquake studies. Natural disasters, such as earthquakes, should be considered a public health issue affecting maternal and neonatal health in the community.

The aims of the study reported here was to explore the relationship between earthquake and maternal depression and child-rearing in a depopulated community in Japan. An empirically based understanding of the possible influence of the Noto Peninsula earthquake on maternal and neonatal health is important for future policy decisions.

\section{Subjects and methods}

\section{Data collection}

We chose to collect data using a self-rating questionnaire. Three months after the earthquake, a questionnaire was distributed to pregnant women who were receiving routine perinatal care, either by a physician or a midwife, at any of four major hospitals in the most devastated area. The study design was cross-sectional. All of the study participants were pregnant at the time of the earthquake or became pregnant immediately thereafter and were living in the disaster area. Between 25 June 2007 to 31 January 2008, 311 of the 399 questionnaires distributed were returned. Some participants in this panel study completed questionnaires both before and after their deliveries. Among a total of 199 participants, 93 women completed two questionnaires and 19 completed three. Among these, the 155 women who returned one questionnaire after childbirth were analyzed in our study. This study was approved by the Ethics Committee of the Kanazawa Graduate School of Medical Sciences.

\section{Instruments}

Socio-demographic data included the participant's age, marital status, and birth history (primipara/multipara). Perinatal data included gestational age at the time of the earthquake and the number of days since childbirth. These variables were considered to be potential confounding factors.

Earthquake-related factors included whether or not an "evacuation" shelter or temporary housing was used (yes/ no), "fear of the earthquake" (not very fearful/very fearful), "anxiety about earthquakes" during pregnancy (yes/ no), and whether or not there was "house damage" (yes/ no) when the earthquake occurred. All of these earthquakerelated variables were dichotomous.

Maternal psychological status was assessed with the Edinburgh Postnatal Depression Scale (EPDS) developed by Cox in 1987 [20]. Its validity and reliability have been confirmed in the Japanese population [21]. The EPDS scale consists of ten items, each of which is a four-point Likert scale. The total score ranges from 0 to 30 . The cutoff point of the EPDS among Japanese population is a score of 9 [20, 21]. Respondents with scores $>9$ are considered to be at a significantly increased risk of maternal depression. Cronbach's $\alpha$ in this study was 0.83 , indicating adequate internal reliability.

Maternal satisfaction with the delivery was assessed with the Self-Evaluation Scale for Experience of Delivery [22]. This scale consists of 18 items, including "I was relaxed in the face of childbirth", "I accepted childbirth pain open-mindedly", and "My childbirth experience was like what I had wanted", each of which is a five-point Likert scale. These items were constructed referencing some Western studies [23, 24] and were adjusted to reflect the Japanese context. Respondents with higher scores are likely to be more satisfied with their childbirth experience. The total score ranges from 5 to 90 . Cronbach's $\alpha$ in this study was 0.89 , indicating adequate internal reliability.

As child-rearing-related variables, "lactation" (maternal milk/artificial milk or mix) and "trouble with infant care" (yes/no) were also assessed. These two variables were dichotomous.

\section{Statistical analysis}

To evaluate the relationship between variables, Pearson's correlation coefficient $(r)$ or correlation ratio $(\eta)$ was calculated. To explore the significant predictive factors for 
EPDS or "satisfaction with delivery", "lactation", "trouble with infant care", and "fear of the earthquake", stepwise multivariate regression analysis using a forward, stepwise method was performed. The entry and exit criteria were set at $p=0.05$ and $p=0.10$, respectively. For missing data, listwise deletion was used. In all multivariate analyses, adjustment was conducted for age and birth history. As a result, a path diagram representing the relationships between these variables was constructed. A $p$ value $<0.05$ was thought to be statistically significant. Statistical analysis was performed using SPSS (Statistical Package for Social Sciences, Chicago, IL) version 14.0 for Windows.

\section{Results}

The basic characteristics of study participants who experienced the Noto Peninsula earthquake during pregnancy are outlined in Table 1. The mean age ( \pm standard deviation, SD) of the 155 participants was $29.7 \pm 4.7$ years. The mean number of weeks after earthquake exposure was $15.8 \pm 9.06$. The mean number of days after childbirth was $29.7 \pm 11.2$. The mean EPDS score $( \pm \mathrm{SD})$ was $4.2 \pm 4.2$, and the percentage of scores $\geq 9$ was $11.6 \%$.

Correlations between variables are presented in Table 2 . The EPDS scores were significantly correlated with increased "trouble with infant care" $(\eta=0.42, p<0.01)$, increased artificial "lactation" $(\eta=0.31, p<0.01)$, decreased "satisfaction with delivery" $(r=-0.27, p<0.01)$, increased "anxiety about earthquakes" $(\eta=0.26, p<0.01)$. "Birth history" significantly correlated with increased "satisfaction with delivery" $(\eta=0.27, p<0.01)$, decreased "trouble with infant care" $(r=-0.26, p<0.01)$, and decreased $\operatorname{EPDS}(\eta=-0.29, p<0.01)$. "Anxiety about earthquakes" significantly correlated with increased "fear of the earthquake" $(r=0.20, p<0.05)$.

Stepwise multivariate analysis was performed, and the results are presented in Table 3. "Anxiety about earthquakes" was associated with "fear of the earthquake" ( $\beta=0.20, p=0.004)$. The EPDS score was significantly associated with "anxiety about earthquakes" $(\beta=0.30$, $p<0.001)$ and "birth history" $(\beta=-0.23, p=0.01)$. In this model, women who were anxious about experiencing an earthquake during pregnancy and were primipara had an increased prevalence of postnatal depression. The EPDS score was significantly associated with "satisfaction with delivery" $(\beta=-0.28, p=0.01)$, "trouble with infant care" $(\beta=0.47, p<0.001)$, and "lactation" $(\beta=0.31$, $p=0.002)$, respectively. All other explanatory variables were excluded from the model (see footnote to Table 3 ).

Based on these results, a path diagram was depicted (Fig. 1).
Table 1 Basic characteristics of women experiencing an earthquake during pregnancy $(n=155)$

\begin{tabular}{|c|c|}
\hline Basic characteristics & Values/scores \\
\hline \multicolumn{2}{|l|}{ Demographics and maternal factors } \\
\hline Age (years), mean \pm SD (range) & $29.7 \pm 4.7(16-40)$ \\
\hline \multicolumn{2}{|l|}{ Marital status, $n(\%)$} \\
\hline Not married & $1(0.9)$ \\
\hline Married & $116(99.1)$ \\
\hline \multicolumn{2}{|l|}{ Birth history, $n(\%)$} \\
\hline Primipara & $54(42.2)$ \\
\hline Multipara & $74(57.8)$ \\
\hline $\begin{array}{l}\text { Gestational age at earthquake } \\
\text { exposure (weeks), mean } \pm \mathrm{SD} \text { (range) }\end{array}$ & $15.8 \pm 9.06(0-38)$ \\
\hline $\begin{array}{l}\text { Days after childbirth at participation, } \\
\text { mean } \pm \mathrm{SD} \text { (range) }\end{array}$ & $29.7 \pm 11.2(1-68)$ \\
\hline EPDS score, mean \pm SD (range) & $4.2 \pm 4.2(0-22)$ \\
\hline \multicolumn{2}{|l|}{ Trouble with infant care, $n(\%)$} \\
\hline$(-)$ & $120(79.5)$ \\
\hline$(+)$ & $31(20.5)$ \\
\hline \multicolumn{2}{|l|}{ Lactation $(n, \%)$} \\
\hline Maternal milk & $84(55.6)$ \\
\hline Mix & $53(35.1)$ \\
\hline Artificial milk & $14(9.3)$ \\
\hline $\begin{array}{l}\text { Satisfaction with delivery, } \\
\text { mean } \pm \text { SD (range) }\end{array}$ & $70.5 \pm 10.4(41-90)$ \\
\hline \multicolumn{2}{|l|}{ Earthquake-related factors } \\
\hline \multicolumn{2}{|l|}{ House damage, $n(\%)$} \\
\hline$(-)$ & $72(64.3)$ \\
\hline$(+)$ & $40(35.7)$ \\
\hline \multicolumn{2}{|l|}{ Evacuation, $n(\%)$} \\
\hline$(-)$ & $90(70.9)$ \\
\hline$(+)$ & $37(29.1)$ \\
\hline \multicolumn{2}{|l|}{ Fear of the earthquake, $n(\%)$} \\
\hline Not very fearful & $36(30.8)$ \\
\hline Very fearful & $81(69.2)$ \\
\hline \multicolumn{2}{|l|}{ Anxiety about earthquakes, $n(\%)$} \\
\hline$(-)$ & $121(79.1)$ \\
\hline$(+)$ & $32(20.9)$ \\
\hline
\end{tabular}

EPDS Edinburgh Postnatal Depression Scale, $S D$ standard deviation

\section{Discussion}

The mean EPDS score for women who experienced a moderate-scale earthquake during pregnancy was 4.2 , and the percentage of women falling into the high risk category for postnatal depression was $11.6 \%$. A large population study on Japanese women with postnatal depression reported that the percentage who fell into the high risk category was $13.9 \%$ [25], suggesting that our study participants had almost the same prevalence of postnatal depression as that of the general Japanese population. However, this result does not 
Table 2 Correlations between variables

\begin{tabular}{|c|c|c|c|c|c|c|c|c|c|c|}
\hline & 1 & 2 & 3 & 4 & 5 & 6 & 7 & 8 & 10 & 11 \\
\hline 1. Age & 1 & & & & & & & & & \\
\hline 2. Birth history (primipara/multipara) & $0.20 *$ & 1 & & & & & & & & \\
\hline 3. EPDS score & -0.08 & $-0.29 * *$ & 1 & & & & & & & \\
\hline 4. Trouble with infant care $(-/+)$ & -0.09 & $-0.26 * *$ & $0.42 * *$ & 1 & & & & & & \\
\hline 5. Lactation & 0.03 & 0.03 & $0.31 * *$ & 0.08 & 1 & & & & & \\
\hline 6. Satisfaction with delivery & -0.02 & $0.27 * *$ & $-0.27 * *$ & $-0.16^{\dagger}$ & -0.12 & 1 & & & & \\
\hline 7. House damage $(-/+)$ & -0.03 & -0.09 & 0.04 & 0.05 & 0.09 & -0.09 & 1 & & & \\
\hline 8. Evacuation $(-/+)$ & -0.10 & -0.06 & 0.08 & -0.02 & 0.09 & 0.05 & $0.21 *$ & 1 & & \\
\hline 10. Fear of the earthquake $(-/+)$ & -0.04 & -0.14 & $0.16^{\dagger}$ & 0.04 & 0.10 & -0.10 & $0.17^{\dagger}$ & $0.15^{\dagger}$ & 1 & \\
\hline 11. Anxiety about earthquakes $(-/+)$ & -0.01 & -0.12 & $0.26^{* *}$ & 0.07 & 0.07 & -0.08 & 0.08 & $0.17 *$ & $0.20 *$ & 1 \\
\hline
\end{tabular}

${ }^{\dagger} p<0.10 ; * p<0.05 ; * * p<0.01$

Table 3 Results of multiple regression analyses

\begin{tabular}{|c|c|c|c|c|c|c|c|}
\hline Model & Dependent variable & Independent variable & $\begin{array}{l}\text { Partial regression } \\
\text { coefficient }(B)\end{array}$ & $\begin{array}{l}\text { Standard } \\
\text { error }\end{array}$ & $\begin{array}{l}\text { Standardized } \\
\text { regression } \\
\text { coefficient }(\beta)\end{array}$ & $t$ & $p$ value \\
\hline \multirow[t]{2}{*}{$1^{\mathrm{a}}$} & Anxiety about earthquakes & Fear of the earthquake $(-/+)$ & 0.17 & 0.08 & 0.20 & & 0.040 \\
\hline & & Adjusted $R^{2}$ & & & & & 0.029 \\
\hline \multirow[t]{3}{*}{$2^{\mathrm{b}}$} & EPDS score & Anxiety about earthquakes $(-/+)$ & 3.06 & 0.91 & 0.30 & 3.35 & 0.001 \\
\hline & & Birth history (primipara/multipara) & -1.94 & 0.75 & -0.23 & -2.57 & 0.011 \\
\hline & & Adjusted $R^{2}$ & & & & & 0.158 \\
\hline \multirow[t]{2}{*}{$3^{\mathrm{c}}$} & Trouble with infant care & EPDS score & 0.05 & 0.01 & 0.47 & & $<0.001$ \\
\hline & & Adjusted $R^{2}$ & & & & & 0.213 \\
\hline \multirow[t]{2}{*}{$4^{\mathrm{d}}$} & Lactation & EPDS score & 0.02 & 0.01 & 0.31 & & 0.002 \\
\hline & & Adjusted $R^{2}$ & & & & & 0.084 \\
\hline \multirow[t]{2}{*}{$5^{e}$} & Satisfaction with delivery & EPDS score & -0.67 & 0.25 & -0.28 & -2.73 & 0.010 \\
\hline & & Adjusted $R^{2}$ & & & & & 0.066 \\
\hline
\end{tabular}

${ }^{a}$ Age, birth history, evacuation, and house damage were excluded from the model

b Age, evacuation, house damage, and fear of the earthquake were excluded from the model

c Age, evacuation, anxiety about earthquakes, house damage, and fear of the earthquake were excluded from the model

d Age, birth history, evacuation, anxiety about earthquakes, house damage, and fear of the earthquake were excluded from the model

e Age, birth history, evacuation, anxiety about earthquakes, house damage, and fear of the earthquake were excluded from the model

necessarily mean that pregnant women who experienced the Noto Peninsula earthquake did not experience disasterrelated stress. Rather, it may be a reflection of the fact that depression levels are relatively lower in rural areas. Another interpretation of this result is selection bias: women with severe psychiatric symptoms may have been excluded from our study, thereby resulting in an underestimation of the prevalence of depression.

The results of our study indicate that "anxiety about earthquakes" during pregnancy were significantly associated with postnatal depression among the study participants. Previous studies have demonstrated that the correlation between anxiety and depression is generally high [26], with one study reported a calculated correlation coefficient of 0.5 [27]. This association was also seen in the our study.
Additionally, our results show that women who experience anxiety about earthquakes also tend to be very fearful about the possible occurrence of earthquakes. Taken together, these results suggest that the earthquake may have aroused negative psychological symptoms, such as fear and anxiety, in the pregnant women participating in our study, which in turn may have led to postnatal depression. Therefore, women who have fears or anxiety about earthquakes may be more at risk of postnatal depressive symptoms, or vice versa, as we were unable to determine the direction of the causal relationship within the framework of our study.

It should be noted, however, that objective indicators of earthquake damage such as "evacuation" and "house damage" did not reach the level of statistical significance against the outcome variables. One possible interpretation 
Fig. 1 Path diagram regarding earthquake factors that relate childbirth and child-rearing outcome factors

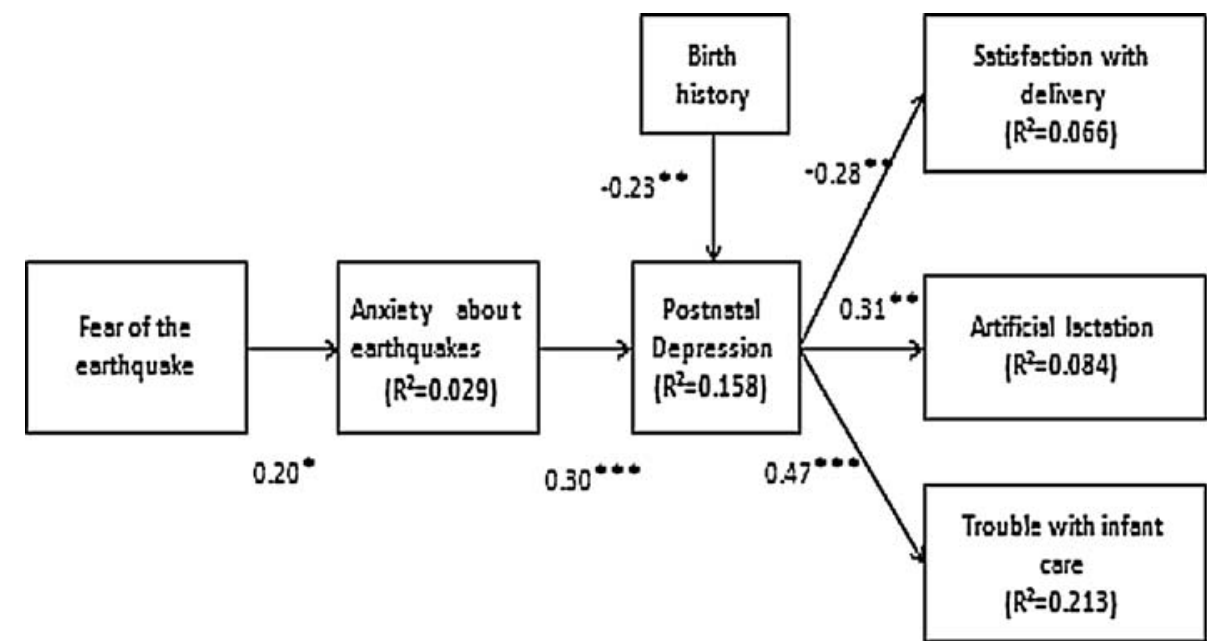

$* 0.05, *<0.01, * * 0.001$ is that the participants who responded to the questionnaire experienced minimal physical and material damage. The fact that no injuries were reported among these participants may contribute to the lack of association between depression and physical and material damage. Selection bias in this study may also be one reason why study participants had minimal physical and material damage. Consequently, any interpretation of the associations found in this study must take into account bias due to missing data in the exploratory variables.

A large number of studies on postnatal depression have been conducted on populations other than earthquake survivors. The findings of these revealed that a number of sociodemographic and personal factors, such as single motherhood [28], teenage pregnancy [29], lack of support from a spouse [30], presence of extended family [31], and social isolation $[32,33]$, are significant risk factors for the development of postnatal depression. Our study may be the first to assess earthquake-affected perinatal women with the EPDS scale. We found that primiparous women living in the disaster area were at significant risk of postnatal depression. Primiparous women, due to their lack of experience with pregnancy, childbirth, and child-rearing, may be more vulnerable to earthquake-induced stress. Thus, support for women with risk factors for postnatal depression identified in previous studies and our study is of critical importance following an event such as a medium-scale earthquake.

The results from previous studies also indicated that postnatal depression in populations other than earthquake survivors may be significantly related to cessation of breast-feeding [8, 34], degradation of mother-infant attachment [29], more concerns about the baby [35], and unfavorable patterns of seeking healthcare services [36]. These outcomes may also be applicable for women with high EPDS scores living in the disaster area. Our study found that EPDS score was significantly associated with a lower "satisfaction with delivery", lower prevalence of breast-feeding, and increased "trouble with infant care". These results are basically consistent with those of earlier studies in terms of a number of outcomes related to maternal postnatal depression.

In summary, based on the results of our study, we were unable to determine a direct relationship between earthquake-related factors and child-rearing variables. However, earthquake-related factors are associated with postnatal depression, and postnatal depression may then have lead to degradation of maternal child-rearing (see Fig. 1). Thus, earthquake survivors with a high EPDS score may be at increased risk of experiencing negative effects on their child-rearing abilities, and a screening system using the EPDS may be of significant value in non-catastrophic disaster areas. Therefore, when formulating an appropriate support system for perinatal women with high EPDS, we should strengthen and expand support not only in ordinary situations but also under less extraordinary circumstances, especially in the aftermath of a non-catastrophic disaster.

There are a number of limitations to our study. This was a cross-sectional study and as such it was not possible to determine causal relationships. There was a potential bias due to convenience sampling and self-report bias, and the results may not be applicable to all perinatal women inhabiting depopulated or disaster-affected communities. Additionally, missing values may increase the bias. However, literature on this subject is sparse, and the findings of our study make an important contribution to the prediction of the long-term impact of non-catastrophic natural disasters on child-rearing in depopulated communities. 
Acknowledgments The authors would like to thank the participants of this study. We would also like to thank those who made this study possible: Dr. Kouya Aoyama at Wajima Hospital, Dr. Yukio Nakahama at Anamizu General Hospital, Dr. Tomoko Fujita at Noto General Hospital, and Dr. Takafumi Kohama at Keiju General Hospital.

\section{References}

1. Tanaka H, Oda J, Iwai A, Kuwagata Y, Matsuoka T, Takaoka M, et al. Morbidity and mortality of hospitalized patients after the 1995 Hanshin-Awaji earthquake. Am J Emerg Med. 1999;17(2): 186-91.

2. Kuwabara H, Shioiri T, Toyabe S, Kawamura T, Koizumi M, ItoSawamura M, et al. Factors impacting on psychological distress and recovery after the 2004 Niigata-Chuetsu earthquake, Japan: community-based study. Psychiatry Clin Neurosci. 2008;62(5): 503-7.

3. Carr VJ, Lewin TJ, Webster RA, Kenardy JA, Hazell PL, Carter GL, et al. Psychological sequelae of the 1989 Newcastle earthquake: II. Exposure and morbidity profiles during the first 2 years post disaster. Psychol Med. 1997;2(1):167-78.

4. Montazeri A, Baradaran H, Omidvari S, Azin SA, Ebadi M, Garmaroudi G, et al. Psychological distress among Bam earthquake survivors in Iran: a population-based study. BMC Public Health. 2005;5:4.

5. Cao H, Mcfarlane AC, Klimids S. Prevalence of psychiatric disorder following the 1988 Yun Nan (China) earthquake: the first 5-month period. Soc Psychiatry Psychiatr Epidemiol. 2003;38(4):204-12.

6. Glynn LM, Wadhwa PD, Dunkel-Schetter C, Chicz-Demet A, Sandman CA. When stress happens matters: effects of earthquake timing on stress responsibility in pregnancy. Am J Obstet Gynecol. 2001;184(4):637-42.

7. Chang HL, Chang TC, Lin TY, Kuo SS. Psychiatric morbidity and pregnancy outcome in a disaster area if Taiwan 921 earthquake. Psychiatry Clin Neurosci. 2002;56:139-44.

8. Ruvalcaba RH. Stress-induced cessation of lactation. West J Med. 1987;146:228-30.

9. Fukuda M, Fukuda K, Shimizu T, Møller H. Decline in sex ratio at birth after Kobe earthquake. Hum Reprod. 1998;13(8):2321-2.

10. Lederman SA, Rauh V, Weiss L, Stein JL, Hoepner LA, Becker $\mathrm{M}$, et al. The effects of the World Trade Center event on birth outcomes among term deliveries at three lower Manhattan hospitals. Environ Health Perspect. 2004;112(17):1772-8.

11. Laplante DP, Barr RG, Brunet A, Galbaud du Fort G, Meaney ML, Saucier JF, et al. Stress during pregnancy affects general intellectual and language functioning in human toddlers. Pediatr Res. 2004;56(3):400-10.

12. Engel SM, Berkowitz GS, Wolff MS, Yehuda R. Psychological trauma associated with the World Trade Center attacks and its effect on pregnancy outcome. Paediatr Perinat Epidemiol. 2005;19(5):334-41.

13. Porter CL, Hsu HC. First-time mothers' perceptions of efficacy during the transition to motherhood: links to infant temperament. J Fam Psychol. 2003;17:54-64.

14. Teti DM, Galfand DM. Behavioral competence among mothers of infants in the first year: the educational role of maternal selfefficacy. Child Dev. 1991;62:918-29.

15. Murray L, Fiori-Cowley A, Hooper R, Cooper P. The impact of postnatal depression and associated adversity on early motherinfant interactions and later infant outcome. Child Dev. 1996; 67:2512-26.
16. Beck CT. The effects of postpartum depression on child development: a meta-analysis. Arch Psychiatr Nurs. 1998;12:12-20.

17. Proctor LJ, Fauchier A, Oliver PH, Ramos MC, Rios MA, Margolin G. Family context and young children's responses to earthquake. J Child Psychol Psychiatry. 2007;48(9):941-9.

18. Swenson CC, Saylor CF, Powell MP, Stokes SJ, Foster KY, Belter RW. Impact of a natural disaster on preschool children: adjustment 14 months after a hurricane. Am J Orthopsychiatry. 1996;66(1):122-30.

19. Curtis T, Miller BC, Berry EH. Changes in reports and incidence of child abuse following natural disasters. Child Abuse Negl. 2000;24(9):1151-62.

20. Cox JL, Holden JM, Sagovsky R. Detection of postnatal depression: development of the 10-interm Edinburgh postnatal depression scale. Br J Psychiatry. 1987;150:782-6.

21. Okano T, Murata M, Masuji F. Validation and reliability of a Japanese version of the EPDS. Arch Psychiatr Diagn Clin Eval. 1996;7:525-33.

22. Tokiwa Y, Imazaki Y. Design of self-evaluation scale for experience of delivery and study of its reliability and validity (article in Japanese). Nihon Kango Kagakkaishi. 2000;20(1):1-9.

23. Jaccqueline D. The factor of structure of the perception of birth scale. Nurs Res. 1996;45(2):73-86.

24. Ellen H, Simmons-Tropea D. The Labor Agency Scale. Psychometric properties of an instrument measuring control during childbirth. Res Nurs Health. 1987;10:301-10.

25. Suzumiya H, Yamashita H, Yoshida K. Hoken Kikan ga Jishisuru Boshi houmon taisyosha no sango utzu byou zenkoku tashisetsu chosa (article in Japanese). Kousei no Shihyo. 2004;51(10):1-5.

26. Stavrakaki C, Vargo B. The relationship of anxiety and depression: a review of the literature. Br J Psychiatry. 1986;149:7-16.

27. Clark DA, Beck AT, Brown G. Cognitive mediation in general psychiatric outpatients: a test of the content-specificity hypothesis. J Pers Soc Psychol. 1989;56(6):958-64.

28. Adewuya AO, Fatoye FO, Ola BA, Ijaodola OR, Ibigbami SM. Sociodemographic and obstetric risk factors for postpartum depressive symptoms in Nigerian women. J Psychiatr Pract. 2005;11(5):353-8.

29. Wahn EH, Nissen E. Sociodemographic background, lifestyle and psychosocial conditions of Swedish teenage mothers and their perception of health and social support during pregnancy and childbirth. Scand J Public Health. 2008;36(4):415-23.

30. Milgrom J, Gemmill AW, Bilszta JL, Hayes B, Barnett B, Brooks $\mathrm{J}$, et al. Antenatal risk factors for postnatal depression: a large prospective study. J Affect Disord. 2008;108(1-2):147-57.

31. Kuscu MK, Akman I, Karabekiroglu A, Yurdakul Z, Orhan L, Ozdemir N, et al. Early adverse emotional response to childbirth in Turkey: the impact of maternal attachment styles and family support. J Psychosom Obstet Gynaecol. 2008;29(1):33-8.

32. Akman I, Kuscu MK, Yurdakul Z, Ozdemir N, Solakoğlu M, Orhon L, et al. Breastfeeding duration and postpartum psychological adjustment: role of maternal attachment styles. J Paediatr Child Health. 2008;44(6):369-73.

33. Nielsen FD, Videbech P, Hedegaard M, Dalby SJ, Secher NJ. Postpartum depression: identification of women at risk. Br J Obstet Gynaecol. 2000;107(10):1210-7.

34. Sato Y, Kato T, Kakee N. Support from advisors on child rearing for alleviating maternal anxiety and depressive symptoms among Japanese women. J Epidemiol. 2008;18(5):234-41.

35. Minkovitz CS, Strobino D, Scharfstein D, Hou W, Miller T, Mistry KB, et al. Maternal depressive symptoms and children's receipt of health care in the first 3 years of life. Pediatrics. 2005;115(2):306-14.

36. Barnett B, Parker G. Possible determinants, correlates and consequences of high levels of anxiety in primiparous mothers. Psychol Med. 1986;16(1):177-85. 